\title{
On the relationship between flux transfer events, temperature enhancements, and ion upflow events in the cusp ionosphere
}

\author{
A.. Skjæveland, ${ }^{1,2}$ J. Moen, ${ }^{2}$ and H. C. Carlson ${ }^{3}$ \\ Received 19 January 2011; revised 9 June 2011; accepted 15 July 2011; published 11 October 2011.
}

[1] A transit of the dayside aurora across the field-of-view of the EISCAT Svalbard Radar occurred on 20 December 1998. This offered an excellent opportunity to study the spatial structure of the cusp/cleft aurora using meridian scanning photometer and incoherent scatter radar. We were able to identify distinct regions of upflow driven by ion heating (type 1) and upflow driven by electron heating (type 2) around poleward moving auroral forms, a transient auroral feature tied to flux transfer events. A quiet period before the auroral transit allowed us to estimate a neutral temperature profile, which enabled calculation of the ion-neutral relative wind. We found evidence for purely ion heating-driven upflow equatorward of the cusp auroral boundary, and for electron heating-driven upflow near the equatorward auroral boundary. The greatest upflow occurred near the center of the cusp aurora when both ion and electron temperatures were enhanced. The observed upflows were greater than expected from ambipolar diffusion alone, suggesting that ion-neutral frictional heating did contribute to upflow events in most cases. The great variability observed in ion temperature indicates that the ion flow was greatly structured within the aurora. Type 1-2 upflows may be considered as spatial structures of active cusp. Upflows are observed at various times in their evolution, and one upflow event, estimated to be 5-10 minutes old, showed a lifting of the F region of some $100 \mathrm{~km}$, indicating a hybrid of type 1 and type 2 .

Citation: Skjæveland, Å., J. Moen, and H. C. Carlson (2011), On the relationship between flux transfer events, temperature enhancements, and ion upflow events in the cusp ionosphere, J. Geophys. Res., 116, A10305, doi:10.1029/2011JA016480.

\section{Introduction}

[2] Cusp dynamics have been systematically explored by optical and radar techniques over the past couple of decades. Poleward moving auroral forms (PMAFs) and transient flow channels are both important features of cusp dynamics that need to be considered in order to describe the initial upward acceleration of ions in the cusp ionosphere, which is the major objective of this paper. This lends order to these features, within the context of their underlying driving physical processes, and thereby extends ability to evaluate their implications.

[3] The ion upflow phenomenon commonly observed in the upper $\mathrm{F}$ layer in the auroral zone has been studied quite extensively [cf. Shelley et al., 1976; McCrea et al., 1991; Wahlund et al., 1992; Davies et al., 1995; Endo et al., 2000; Ogawa et al., 2003, 2009]. An important distinction is that upflow refers to plasma moving upward along the geomagnetic field at or above some speed threshold. Outflow refers to plasma that has achieved escape velocity and is leaving the ionosphere. Wahlund et al. [1992] used the

\footnotetext{
${ }^{1}$ University Centre in Svalbard, Longyearbyen, Norway.

${ }^{2}$ Department of Physics, University of Oslo, Oslo, Norway. USA.

${ }^{3}$ Space Weather Center, CASS, Utah State University, Logan, Utah,

Copyright 2011 by the American Geophysical Union. 0148-0227/11/2011JA016480
}

EISCAT Tromsø incoherent scatter radars to divide auroral ion upflow into two distinct classes, based on whether the plasma within and underneath the upflowing plasma was enhanced primarily in ion temperature $\left(T_{i}\right)$ or electron temperature $\left(T_{e}\right)$. Upflows dominated by enhanced $T_{i}$ were labeled type 1, while upflows dominated by enhanced $T_{e}$ were labeled type 2 . Type 2 upflows were found to be more common and generally more intense than type 1. Strangeway et al. [2005] found that ion outflow correlated with ion frictional heating/joule heating and with soft electron precipitation. However, these energy inputs alone were not found able to create ion outflow, but could cause upflow up to a region in which further energization can be facilitated by some instabilities and/or ELF wave action.

[4] The thermospheric response to heating is dramatically different in the E region and the F region. Due to the much lower atmospheric density in the F region, the same amount of energy input is able to cause much greater atmospheric expansion and upwelling, and the response time is very short, on the order of a minute [Carlson, 1998, 2007]. Thermal response times of ionospheric cusp plasma are also on the order of a minute [Carlson et al., 2004]. In the cusp, since soft electron precipitation deposits its energy as electron heating primarily in the $\mathrm{F}$ region, it is considered an important driver of ionospheric upflow. Ogawa et al. [2003] mapped upflow and downflow occurrence in various magnetospheric region footpoints, and showed that most 
$F$ region ionospheric upflows were associated with soft $(<0.5 \mathrm{keV})$ electron precipitation, although such precipitation could exist without upflow, particularly in the boundary plasma sheet. Moen et al. [2004a] and later Ogawa et al. [2009] showed that upflow above the EISCAT Svalbard Radar (ESR) site near magnetic noon is usually simultaneous with enhanced $T_{e}$ and/or $T_{i}$. Moen et al. [2004a] were the first to tie ion upflow events to cusp auroral transients of the PMAF category commonly attributed to transient magnetopause reconnection or flux transfer events (FTEs) [e.g., Vorobjev et al., 1975; Sandholt et al., 1986, 1989, 1990, 1993, 1998; Moen et al., 1995, 1996a, 1998, 2001; Fasel, 1995; Sigernes et al., 1996; Oksavik et al., 2005].

[5] Mesoscale ion flow channels are another well documented characteristic feature of the cusp. Pinnock et al. [1993, 1995] identified a class of longitudinally extended flow channel events (FCEs) using the PACE HF radar. The flow direction of FCEs was found to be consistent with the magnetic tension pull on newly open flux. The same category of events was further elaborated and termed pulsed ionospheric flows (PIFs) by Provan et al. [1998, 2002]. Moen et al. [2004b] found intensifications in $T_{i}$ in the cusp recurring on a $\sim 10$ minute time scale, indicating that frictional heating was modulated by time-varying reconnection. Lockwood and Wild [1993] and Moen et al. [1995, 2007] found pulsed return flow on closed field lines consistent with the Cowley and Lockwood [1992] model of flow generation by pulsed reconnection. Rinne et al. [2007] identified a new class of cusp flow channels opposing the direction of background convection and the magnetic tension force, and which were therefore named reversed flow events (RFEs). Moen et al. [2008] addressed the relationship of this class of events to Birkeland current arcs.

[6] Hence, the cusp ionosphere is a very dynamic region with mesoscale plasma flow channels that can give rise to type 1 and type 2 upflows separately or simultaneously. Due to the dynamic nature of the ionospheric cusp that includes a combination of convection channels, electron beam/sheets and flow shears, it is a challenging task to examine by pencil-beam incoherent scatter radar. Events may form outside the radar field of view and travel over it, or may form inside the radar and move out of the field of view. Moen et al. [2004a] presented a rather ideal combination of ESR and meridian scanning photometer (MSP) data from Svalbard, and found a one-to-one correspondence between PMAFs and ion upflow events. They found that the ion upflow events broadened with altitude in characteristic V-shape and suggested that each of these PMAFs were associated with an inverted $\mathrm{V}$ potential structure moving over the radar.

[7] Here we are going to further investigate the data set presented by Moen et al. [2004a] with particular focus on differentiating between the upflow effect of $T_{e}$ and $T_{i}$ enhancements in the cusp. It is a very fortunate data set where the radar was first situated equatorward of the cusp aurora, and as the polar cap expanded, ESR probed the aurora containing a sequence of PMAFs, and finally the radar ended up on the poleward side of the cusp aurora, all in just over an hour near noon MLT. We will demonstrate that type 1 (frictional heating) upflow occurred equatorward of the cusp aurora. Type 2 upflows were observed near the equatorward and the poleward borders of the cusp aurora. It will be shown that the strongest upflow events occur within the cusp aurora when $T_{i}$ and $T_{e}$ are simultaneously elevated. We will also attempt to examine the possible anisotropy which may result from ion frictional heating. For this reason we will refer to the ion temperature as measured by the ESR as $T_{i \|}$ (field-aligned component of $T_{i}$ ).

\section{Ground Instrumentation}

[8] Our study uses data from 20 December 1998. The EISCAT Svalbard Radar (ESR) is an incoherent scatter radar facility located in Longyearbyen $\left(78.20^{\circ} \mathrm{N}, 15.82^{\circ} \mathrm{E}\right)$. The radar ran the "GUP3" mode, where the 32-meter antenna was pointing parallel to the $\mathrm{F}$ region geomagnetic field (180.6 ${ }^{\circ}$ azimuth angle, $81.6^{\circ}$ elevation). The GUP3 mode is a combined $\mathrm{E}$ region and $\mathrm{F}$ region experiment using both alternating code and long pulse techniques. (See, e.g., McCrea et al. [2000] and Lockwood et al. [2000] for a detailed description of the radar mode, and Wannberg et al. [1997] for a description of the radar facility.) We have used the processed $F$ region data from the MADRIGAL database with a one-minute integration time in this paper.

[9] The UiO Meridional Scanning Photometer (MSP), located in $\mathrm{Ny}-\AA$ Alesund (NYA, $78.9^{\circ} \mathrm{N}, 12^{\circ} \mathrm{E}$ ), was pointing $32^{\circ}$ west of geographic north, measuring the auroral intensity along the scan plane, from $80^{\circ}$ north of zenith to $80^{\circ}$ south of zenith, in several simultaneous wavelengths with a scan interval of 20 seconds. This instrument was used to observe the latitudinal movement and intensity of the $630.0 \mathrm{~nm}$ aurora. An all-sky camera (ASC) was used to determine the zonal motion of the auroral features, and to investigate small optical events. As illustrated in Figure 1, the location of the ESR beam indicated by a white circle is in close vicinity of the scan plane of the MSP marked by the yellow line. When comparing ESR and MSP data we are going to assume $250 \mathrm{~km}$ emission altitude for the $630.0 \mathrm{~nm}$ emissions.

\section{Observations}

[10] The Kp index was steady at $3^{-}$(2.7) during the observation period. This is a low to moderate value, indicating some geomagnetic activity, but well below storm level. The $\mathrm{Z}$ component of the interplanetary magnetic field (IMF $B_{z}$ ) was predominantly negative, but with some brief positive excursions. IMF $B_{y}$ was mostly positive.

[11] Figure 2 shows the radar and the MSP data we will examine in this paper. Figure $2 \mathrm{a}$ shows the electron density versus altitude and time from the long pulse analysis of the $\mathrm{F}$ region from $218-600 \mathrm{~km}$ altitude. Figures $2 \mathrm{~b}$ and $2 \mathrm{c}$ show the $T_{e}$ and $T_{i \|}$, respectively, and Figure $2 \mathrm{~d}$ shows fieldaligned component of ion velocity $\left(v_{i \|}\right)$. Figure $2 \mathrm{e}$ shows the $630.0 \mathrm{~nm}$ MSP data, with a white line at $32^{\circ}$ south-of-zenith angle corresponding to the radar beam location at $250 \mathrm{~km}$ altitude. All times are in UT unless otherwise specified, and ESR passed magnetic local noon (12 MLT) around 08:50 UT. We will discuss the contributions of $T_{e}$ heating and $T_{i \|}$ heating to ion upflow. We will also discuss the (scalar) fieldperpendicular ion velocity relative to the neutral wind, which we will denote $\left|v_{i \perp}-v_{n}\right|$.

[12] From Figure 2e we see that the cusp aurora was situated well north of the ESR beam until 08:45 UT when the aurora underwent an equatorward movement for an hour 


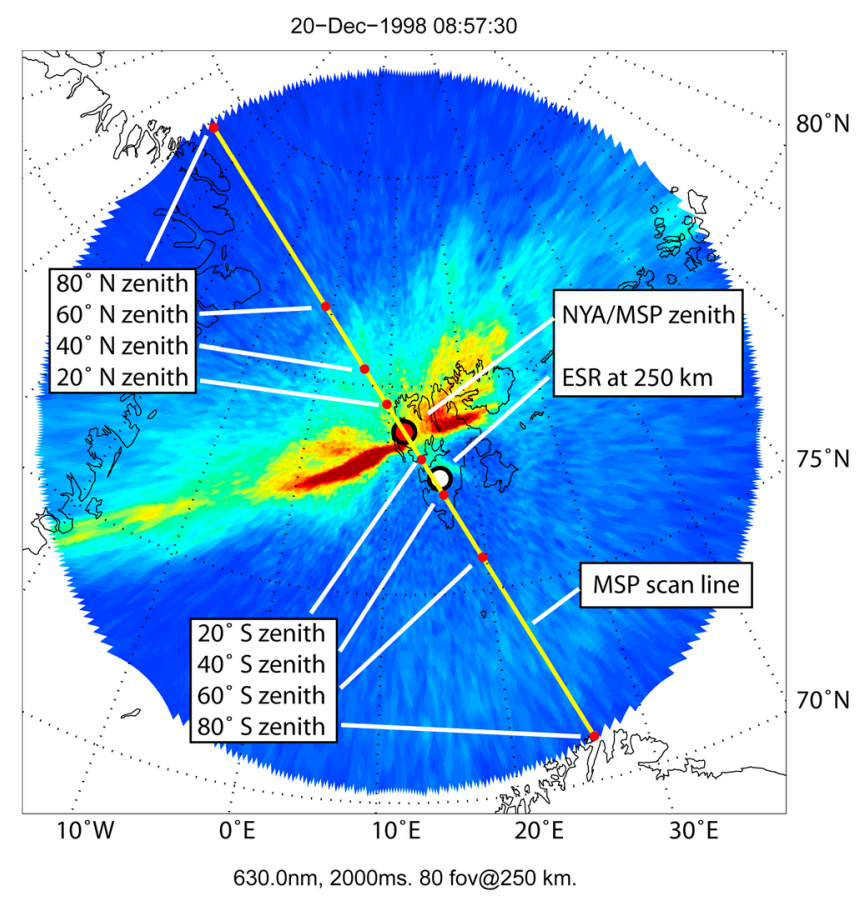

Figure 1. Geometry of the experiment, superimposed on an $630.0 \mathrm{~nm}$ all-sky image projected onto a map. The yellow line indicates the MSP scan plane, the large red circle indicates $\mathrm{Ny}$-Ålesund, and the white circle indicates the ESR volume closest to the MSP plane projected at $250 \mathrm{~km}$. The small red circles along the MSP scan plane mark $20^{\circ}, 40^{\circ}, 60^{\circ}$ and $80^{\circ}$ north/south of zenith in the MSP keogram.

until 09:50 UT, passing through the radar beam. ASC images show that in addition to the poleward motion seen in the MSP data, auroral features underwent westward motion throughout the observation period. Bursts of strongly elevated $T_{e}$ in Figure $2 \mathrm{~b}$ coincide with auroral intensifications, and transient optical intensifications were observed during the transit of the aurora through the radar beam. The incoherent scatter radar signature of cusp precipitation is elevated electron densities below about $200 \mathrm{~km}$ and elevated electron temperatures much above about $130 \mathrm{~km}$ [cf. Doe et al., 2001; Moen et al., 2004b], below which the electron gas is tightly thermally coupled to neutrals by collisions. Because other processes can also heat the electron gas, absence of elevated $T_{e}$ means absence of auroral electron precipitation, but presence of elevated $T_{e}$ needn't mean presence of auroral precipitation.

[13] $T_{e}$ was continuously enhanced from $\sim 09: 02$ until 10:00. $T_{i \|}$ showed a more event-like structure when the radar beam was near and inside the cusp aurora (Figure 2c), subsiding between each event to a lower temperature.

[14] Ion upflow (Figure 2d) occurred nearly continuously from 08:55 to $09: 55$, but structure can be seen in the intensity and altitude of upflow. We found from Figures $2 \mathrm{~d}$ and $2 \mathrm{e}$ that the first instance of ion upflow exceeding $100 \mathrm{~m} / \mathrm{s}$ occurred on the equatorward side of the cusp aurora around 08:55, and the last major upflow event in the sequence occurred around 09:40 UT, when the radar beam was near the poleward edge of the aurora.
[15] SuperDARN quicklook plots based on the mappotential model [Ruohoniemi and Baker, 1998; Ruohoniemi and Greenwald, 2005] are presented in Figure 3. Color and length of the vectors both correspond to magnitude of flow. The grey vectors are data points which are found to be outside the fitting region of the map-potential model, and which are therefore not contributing to the model fit.

[16] The flow pattern in Figure 3a, taken at 08:40 UT, shows a contracted polar cap with the ESR (indicated by black circles in Figure 3) located well south of the polar cap convection pattern. Such a contraction is expected to contract the auroral oval poleward as well. Figure $3 \mathrm{~b}$, from 08:50 UT, shows that the polar cap had expanded, which would then also expand the auroral oval equatorward.

[17] Figures 3c and 3d, taken at 09:20 and 09:50 UT, respectively, show ESR located underneath the cusp inflow region. Figure $3 \mathrm{c}$ shows a poleward component to the ionospheric convection which is not evident in Figure 3d. We can take from this, combined with optical observations, that after 09:40 ESR was situated within a strong zonal convection channel $(>1 \mathrm{~km} / \mathrm{s})$, but poleward of the main cusp aurora. The sequence of PMAFs had stopped (Figure 2e).

[18] The polar cap expansion seen in the MSP data in Figure 2e and the SuperDARN maps in Figures $3 a$ and $3 b$ was explained by Moen et al. [2004a] as due to imbalanced reconnection, first on the nightside, shrinking the polar cap, then on the dayside, expanding it. The rapid equatorward movement of the $630 \mathrm{~nm}$ emission boundary from $\sim 08: 45$ UT in Figure 2e was stimulated by a strengthening in the IMF $B_{z}$ component from weak negative to $-7 \mathrm{nT}$ in the course of 25 minutes. The enhanced magnetopause reconnection facilitated the auroral oval to expand across the radar beam. The rapid increase in electron density seen in Figure 2a from 08:30 onward suggests transport of cold solar EUV ionized plasma toward the cusp inflow region (tongue of ionization) that becomes structured upon encountering cusp dynamics [e.g., Pryse et al., 2004; Moen et al., 2006].

[19] While the timing and exact shape of these convection patterns in Figures 3a and $3 \mathrm{~b}$ may not be precise due to smoothing, low data coverage and inherent assumptions in the map-potential model, these two maps are in good agreement with the expanding polar cap interpretation of the movement of the cusp aurora, and place our ion heating events in the dusk convection cell.

[20] The data set can be sub-divided into 5 regions according to the ESR beam location relative to auroral morphology, marked on Figures 2, 4, and 6 as R1-R5 (not to be confused with the R1-R2 ionosphere-magnetosphere current system). We will discuss Figure 6 in section 4.2. We will now take a closer look at these regions, referring to Figures 2 and 4. We will mark distinct ion heating events, and discuss their relation to ion upflow.

[21] Figure 4a shows $T_{i \|}$ and $T_{e}$ at $302 \mathrm{~km}$ altitude. Figure $4 \mathrm{~b}$ shows the field-aligned ion velocity $\left(v_{i \|}\right)$ measured at $487 \mathrm{~km}$. Figure $4 \mathrm{c}$ shows the calculated ion-neutral relative wind at $302 \mathrm{~km}$. The calculation assumes that ion frictional heating is the only significant ion heating source. The calculation will be described in section 4.1, where we will also discuss the issue of $T_{i}$ anisotropy. Figure $4 \mathrm{~d}$ shows a section of the MSP data, with the zenith angle closest to the radar beam at $250 \mathrm{~km}$ marked with a white line. 


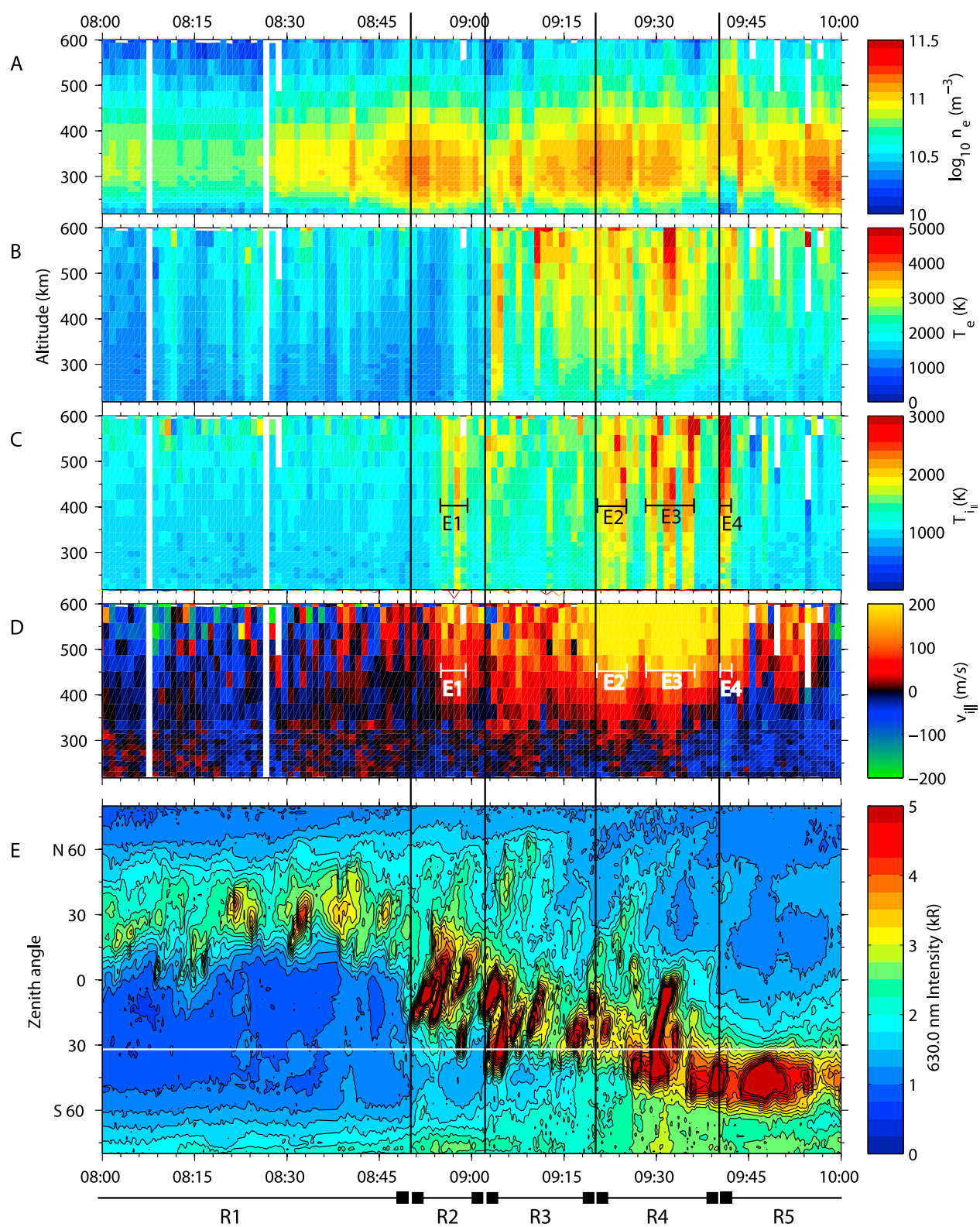

Figure 2. Radar plasma parameters from ESR and $630.0 \mathrm{~nm}$ optical data from Ny-Ålesund MSP on the morning of 20 December 1998. Radar data: (a) $\log _{10}$ electron number density $\left(\mathrm{m}^{-3}\right)$, (b) electron temperature $(\mathrm{K})$, (c) field-aligned component of ion temperature $(\mathrm{K})$, and (d) field-aligned ion velocity $(\mathrm{m} / \mathrm{s}$, positive velocity away from radar). Vertical scale to the left on radar panels is altitude, in kilometers. Time in UT. (e) $630.0 \mathrm{~nm}$ optical intensity (kR) from Ny-Ålesund MSP. Vertical scale in Figure 2e is zenith scan angle. $32^{\circ}$ south zenith angle (approximately corresponding to the ESR at $250 \mathrm{~km}$ projection altitude) is indicated by the white line. Regions $1-5$ marked on bottom. Vertical black lines mark region borders. Ion heating events E1-E4 marked in Figures 2c and 2d.

[22] In region 1, from 08:00 to $\sim 08: 50 \mathrm{UT}$, the ESR was situated well equatorward of the aurora. $T_{i \|}$ was low and steady, slightly less than $1000 \mathrm{~K}$ at $302 \mathrm{~km}$ altitude. $T_{e}$ varied from 1200 to $2000 \mathrm{~K}$. This region is of particular interest to this study as the low and steady $T_{i \|}$ makes it reasonable to assume that the ion gas was in thermal equilibrium with the neutral gas. In section 4.1 we will calculate an average $T_{i \|}$ profile for this time interval to represent the neutral temperature profile.
[23] Region 2 is defined as from 08:50 to 09:02. $T_{i \|}$ rose significantly from $08: 52$ to $08: 58 \mathrm{UT}$, while the aurora approached the radar beam. $T_{e}$ also increased, by approximately the same amount as $T_{i \|}$.

[24] The signatures of magnetic reconnection, expected and observed, have been described in detail by Carlson et al. [2004], including signatures of $T_{e}$ with a response time order a minute and relative location and timing of $T_{i \|}$ and $v_{i \perp}$ enhancements, with all signature boundaries moving poleward. As would then be anticipated the maximum ion 


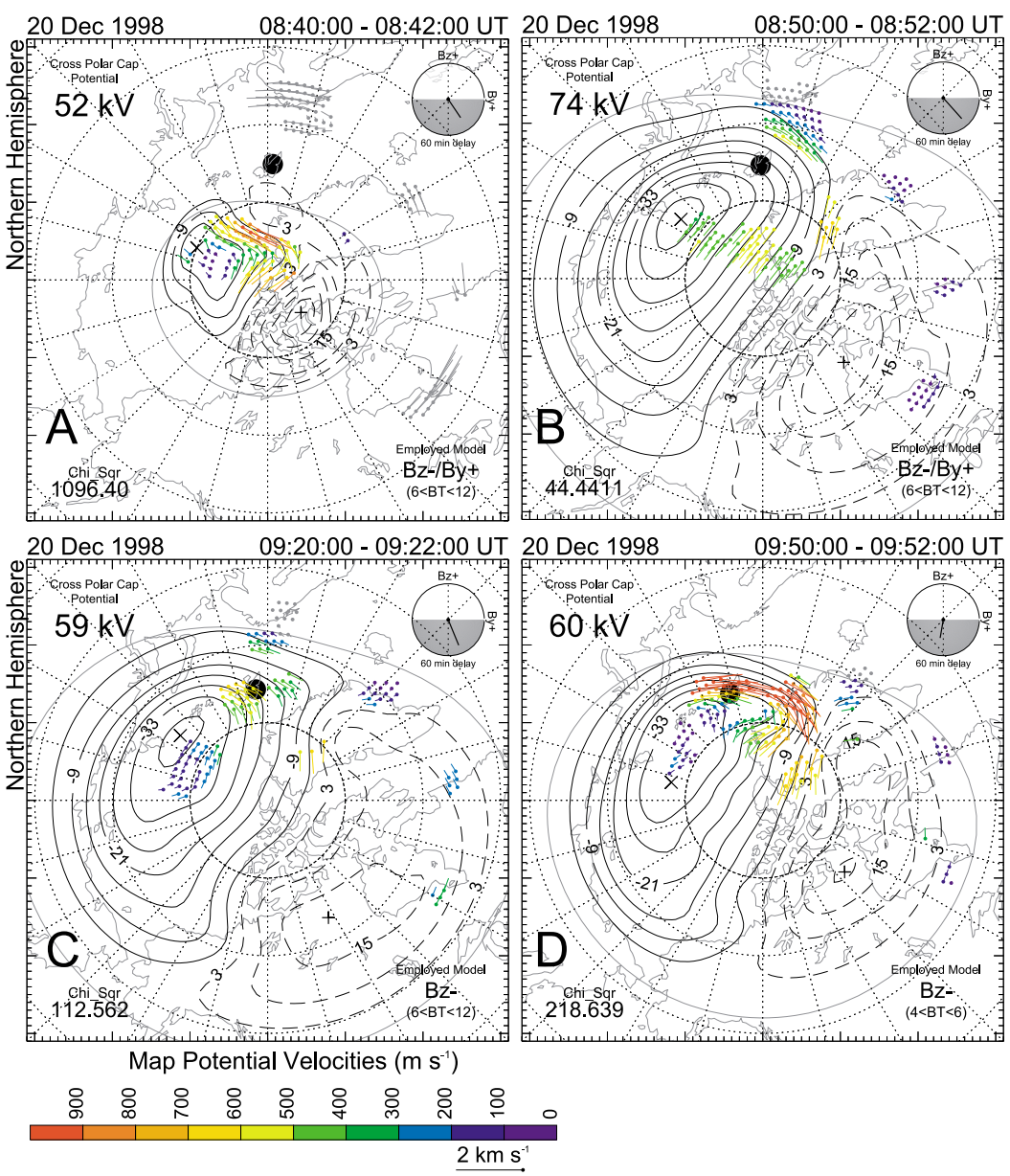

Figure 3. SuperDARN calculated ion drift and polar cap potential for selected times. Location of the EISCAT Svalbard Radar is marked with a black circle.

heating occurred while there was a PMAF, during the high velocity channel found to be associated with PMAFs [Carlson, 1996]. Coincident with the first of these PMAF signatures we observed the first of the ion upflows and first of the $T_{i \|}$ enhancements. We annotate this event as E1 on Figures 2 and 4 . At the time of onset of E1, marked by an increase of $T_{e}\left(T_{i}\right)$ from about $1100(900 \mathrm{~K})$ to about $1800 \mathrm{~K}$, the $v_{i \|}$ changed from $0 \pm 70 \mathrm{~m} / \mathrm{s}$ to steady positive at $50-130 \mathrm{~m} / \mathrm{s}$.

[25] Region 3 is defined as 09:02 to 09:20. At the start of region 3, when the B-parallel radar look angle was poleward of the region where the PMAFs originate (09:04 UT), (cf. Figure 2e), $T_{e}$ jumped dramatically to $3000 \mathrm{~K}$ at $302 \mathrm{~km}$. In contrast to region 2 where it is the frictionally heated ions that appear to transfer heat to the electron gas, here strong precipitating electron fluxes heat the $T_{e}$ well above the $T_{i \|}$, which is still frictionally heated by several hundred degrees (relative to $T_{i \|} \sim T_{n}$ before E1 in Figure 4a), but somewhat less dramatically than the peak of E1. The $T_{e}$ at this onset was the highest seen for this morning, and $T_{e}$ fell to $\sim 2000 \mathrm{~K}$ when the PMAFs departed the beam, with $T_{e}$ continuing to vary between $2000-3000 \mathrm{~K}$ throughout region 3 and 4 as events moved poleward over the radar. From 09:02 to 09:20 UT $T_{i \|}$ was around 1200-1300 K while the radar beam was near the equatorward edge of the auroral band. Relatively stable $T_{i \|}$ persisted and ion upflows were com- parable to that related to E1 throughout this region, with no particular events evident.

[26] In region 4, defined from 09:20 to 09:40 UT, the aurora moved farther equatorward so that the radar beam passed through the middle of the auroral band and reached the poleward edge. During the transit several optical brightenings and PMAFs could be seen, as well as repeated strong intensifications of $T_{i \|}$. The strongest ion upflows were seen in this period. Two $T_{i \|}$ events, E2 and E3, are marked in Figures 2, 4, and 6. E2 was associated with an auroral intensification poleward of the radar beam, similar to $\mathrm{E} 1$, but within the auroral band and hence on elevated $T_{e}$. E3 occurred in association with an intense PMAF passing through the radar beam, and the strong $T_{i \|}$ fluctuations in this event suggests flow shears/narrow flow channels associated with the auroral form. The mean $T_{e}$ in region 4 was slightly higher than in region 3 .

[27] In region 5, from 09:40 to 10:00, the auroral events changed from poleward-moving to purely westward-moving. The radar beam was on the poleward edge of the auroral band. The last large $T_{i \|}$ event, labeled E4 in Figures 2, 4, and 6, occurred 09:40-09:42 UT, at the start of region 5. It is simultaneous with strong upflow. During E4 the entire F layer was lifted significantly, with the peak $n_{e}$ altitude shifted from $\sim 300 \mathrm{~km}$ to $\sim 400 \mathrm{~km}$ altitude. The upflow altitude was 


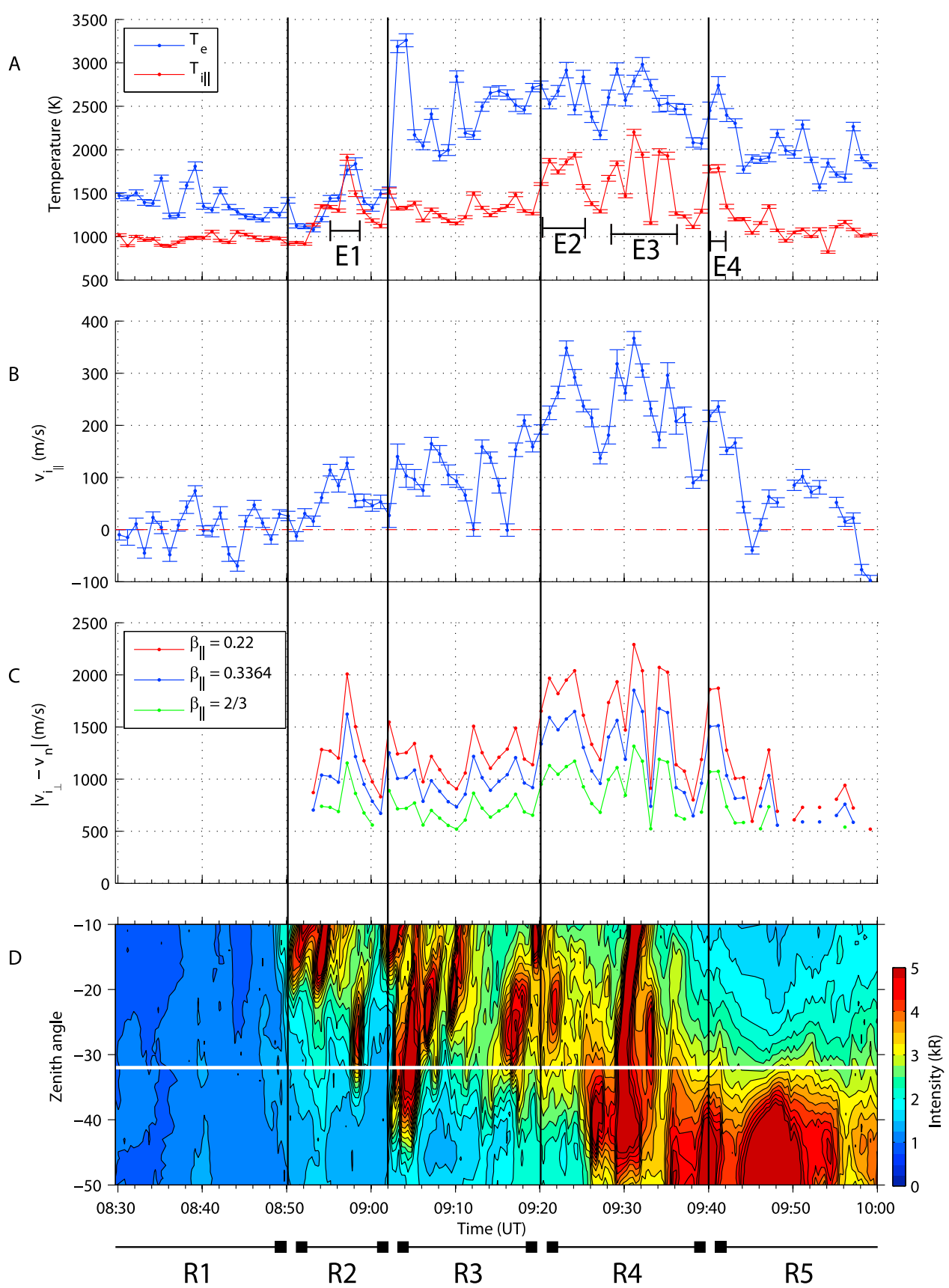

Figure 4. Selected time series. (a) $T_{e}$ and $T_{i \|}$ at $302 \mathrm{~km}$, (b) field-aligned ion upflow velocity at $487 \mathrm{~km}$, (c) calculated $\left|v_{i \perp}-v_{n}\right|$ at $302 \mathrm{~km}$ using $T_{n}$ calculated from quiet $T_{i \|}$ for several values of $\beta_{\|}$, and (d) $630.0 \mathrm{~nm}$ MSP data. Regions and ion heating events marked as in Figure 2.

shifted similarly. Noticeable downflow was observed below $400 \mathrm{~km}$.

[28] After 09:42 UT $T_{i \|}$ fell to 1000-1100 K, while $T_{e}$ fell to $1500-2500 \mathrm{~K}$.

\section{Discussion}

[29] The expansion of the auroral oval across the radar beam on 20 December 1998 provided an opportunity to study ion upflows in three different regions relative to the cusp aurora: Equatorward of the cusp aurora, within the cusp aurora, and on the poleward boundary of the cusp aurora. According to the SuperDARN convection maps, the upflow events observed were located in the cusp inflow region of the dusk cell.

[30] As stated previously, we assume a $250 \mathrm{~km}$ emission altitude for the $630.0 \mathrm{~nm}$ aurora, which correspond to a common volume for ESR and MSP at $32^{\circ}$ south zenith angle for the MSP. Changing the emission altitude assumption to $300 \mathrm{~km}$ gives a zenith angle of $30^{\circ}$, and $350 \mathrm{~km}$ altitude corresponds to $27^{\circ}$. A zenith angle of $30^{\circ}$ does not alter our analysis. For a zenith angle of 


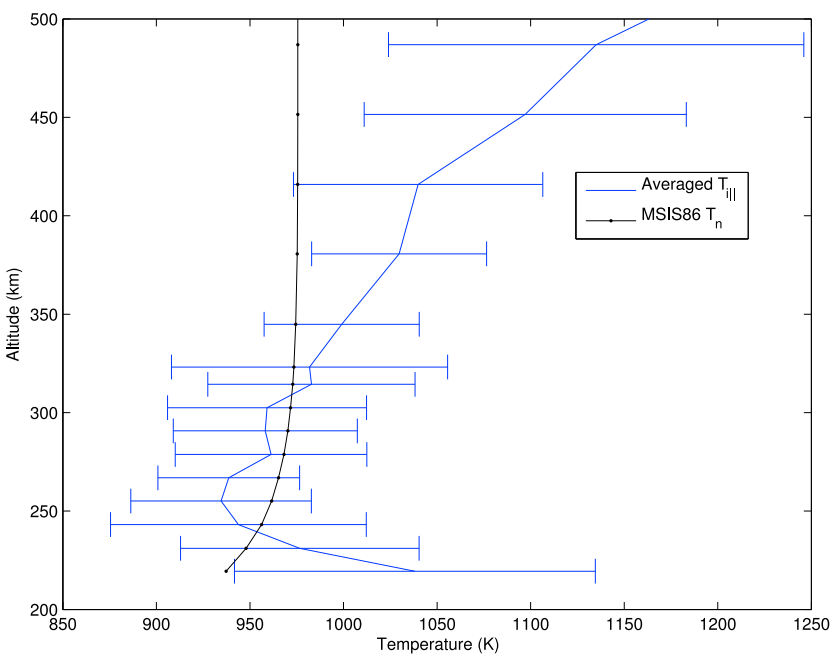

Figure 5. Calculated neutral temperature profile and model MSIS neutral temperature profile.

$27^{\circ}$ the radar beam would still be equatorward of the brightest parts of the PMAFs in region 2, perhaps close enough that we would expect $T_{e}$ enhancements earlier in region 2 than what we observe (cf. Figure 4). The radar beam would be near the center of the auroral band from $\sim 09: 10$ instead of 09:20. Our analysis of upflow in the following discussion would be essentially unchanged.

[31] An emission altitude of $220 \mathrm{~km}$ corresponds to a zenith angle of $36^{\circ}$. In this case the border between region 3 and region 4 would move to $\sim 09: 25$, otherwise the picture is not much affected. The radar beam would still be within the auroral emission in region 3 , almost on the equatorward boundary.

[32] Taking the $630.0 \mathrm{~nm}$ equatorward boundary as a proxy for the open-closed field line boundary, the radar field-of-view was on closed flux up to the moment of the first equatorward expansion of the aurora with onset of PMAFs, presumably due to a southward turning of the IMF. I.e., the first significant ion upflow, simultaneous with ion heating event E1 in Figure 2, likely occurred on closed field lines of central plasma sheet origin [Moen et al., 1996b, 1998; Lorentzen and Moen, 2000]. From then onward ion upflow was observed almost constantly while the aurora transited the radar beam, but modulated by the cusp dynamics. The last ion upflow event in the sequence was observed when the radar beam was near the poleward boundary of the cusp aurora. Before discussing and classifying individual events according to type 1 and type 2 category upflow events (in section 4.3), we will first consider relevant issues related to ion frictional heating. Then we will examine the effect of ambipolar diffusion by calculation (in section 4.2), and last consider ion flow events based on $T_{i \|}$ measurements by ESR (in section 4.3).

\subsection{Neutral Wind and Ion Frictional Heating}

[33] F region frictional heating of the ion gas by collisions with neutrals is given by the ion energy equation [Fedder and Banks, 1972]:

$$
\frac{\mathrm{d} T_{i}}{\mathrm{~d} t}=\nu_{i n}\left(T_{n}-T_{i}+\frac{m_{n}}{3 k}\left|v_{i \perp}-v_{n}\right|^{2}\right)
$$

where $v_{i \perp}$ is the ion drift velocity perpendicular to the geomagnetic field, and $v_{n}$ is the neutral wind velocity. Note that these are vector quantities, although it is customary in the literature to write them as if they are scalars. $k$ is Boltzmann's constant, and $m_{n}$ is the mean molecule mass of the neutral gas. $m_{n}$ is taken from the MSIS 86 model [Hedin, 1987], and $\nu_{\text {in }}$ is the ion-neutral collision frequency, which we take from Schunk and Nagy [2009]:

$$
\nu_{\mathrm{O}^{+} \mathrm{O}}=3.67 \times 10^{-17} n_{n} T_{\text {in }}^{1 / 2}\left[1-0.064 \log _{10}\left(T_{\text {in }}\right)\right]^{2}
$$

where $T_{i n}=\left(T_{i}+T_{n}\right) / 2$ and $n_{n}$ is the neutral number density in $\mathrm{m}^{-3} . T_{i}$ and $T_{n}$ are measured, and $n_{n}$ is taken from the MSIS86 model [Hedin, 1987].

[34] $\nu_{\mathrm{O}^{+} \mathrm{O}}$ varies from $0.7 \mathrm{~s}^{-1}$ for $T_{i}=1000 \mathrm{~K}$ to $0.9 \mathrm{~s}^{-1}$ for $T_{i}=2400 \mathrm{~K}$ at $302 \mathrm{~km}$, and is $\sim 0.08-0.10 \mathrm{~s}^{-1}$ at $416 \mathrm{~km}$. We denote the ion drift velocity $v_{i \perp}$ to distinguish it from the field-parallel ion velocity $v_{i \|}$ component measured directly by the radar.

[35] We estimated $T_{n}$ by averaging $T_{i \|}$ from 08:00 to 08:45 UT, when the radar was measuring a quiet ionosphere well equatorward of the cusp aurora. The calculated $T_{n}$ profile is shown in Figure 5, with the MSIS86 model temperature shown for comparison. The error bars show 1 standard deviation of the averaged $T_{i \|}$. We found $T_{n}=959 \mathrm{~K}$ at $302 \mathrm{~km}$ altitude, with a standard deviation $\sigma T_{n}=53 \mathrm{~K}$. For comparison, the corresponding MSIS86 model temperature was $971 \mathrm{~K}$ at 08:30 UT, increasing to $974 \mathrm{~K}$ at 10:00 UT.

[36] The temperature is well within one standard deviation of the MSIS 86 model temperature from 230 to $350 \mathrm{~km}$. The thermal contact with neutral gas diminishes rapidly with increasing altitude, and above a certain altitude the assumption that the neutral gas is an efficient heat sink for the ion gas no longer holds. Our data suggests that in this case the assumption of isothermal $T_{n}$ and thus $T_{i}$ in the exosphere is consistent with our derivation of $T_{n}$ up to near $400 \mathrm{~km}$. With increasing altitude the ion gas moves from good thermal contact with the cooler neutral gas to better thermal contact with the generally hotter electron gas. We still find that here $T_{i}$ will cool to near equality with $T_{n}$ within its measurement error bars up to approaching $450 \mathrm{~km}$.

[37] Since the ionosphere was convecting rapidly across the radar beam, we were not able to measure separately the spatial and temporal derivatives of $T_{i}$. We therefore have to consider the importance of the derivative term relative to the other terms.

[38] Equation (1) describes the response in ion temperature to a change in ion-neutral relative wind. It is fairly straightforward to show that this ion heating/cooling response has an exponential form with the e-folding time of $\nu_{i n}$. Since the integration time of the radar is 60 seconds, the plasma has time to respond many times over to any relative wind change, and we can set $\mathrm{d} T / \mathrm{d} t=0$ in equation (1), which then simplifies to the steady-state form:

$$
T_{i}-T_{n}=\frac{m_{n}}{3 k}\left|v_{i \perp}-v_{n}\right|^{2}
$$

[39] Equations (1) and (3) do not account for the issue of ion temperature anisotropy. Ion frictional heating in the $F$ region acts perpendicular to the geomagnetic field and causes the ion velocity distribution to deviate from a uni- 
form Maxwellian distribution. The ion temperature measured by incoherent scatter radar then varies with the angle between the radar beam and the geomagnetic field, as the radar only observes the line-of-sight component of the velocity distribution. The theory was described by St-Maurice and Schunk [1977]. A summary that applies to EISCAT experiments was provided by McCrea et al. [1993]. Ignoring ionelectron energy transfer,

$$
\begin{aligned}
& T_{i \|}=T_{n}+\frac{\beta_{\|} m_{n}}{2 k}\left|v_{i \perp}-v_{n}\right|^{2} \\
& T_{i \perp}=T_{n}+\frac{\beta_{\perp} m_{n}}{2 k}\left|v_{i \perp}-v_{n}\right|^{2}
\end{aligned}
$$

where $\beta_{\|}$and $\beta_{\perp}$ are the temperature partition coefficients. The "3-dimensional" ion temperature relates to its components as follows:

$$
T_{i}=\frac{T_{i \|}+2 T_{i \perp}}{3}
$$

The partition coefficients obey the relationship

$$
\beta_{\|}+2 \beta_{\perp} \approx 2 .
$$

[40] Combining equations (4), (5), (6) and (7), it is then possible to reconstruct the 3D $T_{i}$ for a given choice of $\beta_{\|}$.

[41] Various estimates of $\beta_{\|}$exist. St-Maurice and Schunk [1977] calculated $\beta_{\|}$and $\beta_{\perp}$ for the altitude range $\sim 130-300 \mathrm{~km}$ for several ion-neutral collision models. For resonant charge exchange they found $\beta_{\|}=0.3364$. The value of $\beta_{\|}$is not a constant, but varies with altitude and ionospheric conditions. Monte Carlo simulations [Winkler et al., 1992; Barghouthi, 2005] and experiments [McCrea et al., 1993, 1995] reported $\beta_{\|}$values and profiles ranging from 0.22 [Winkler et al., 1992] to 0.5 [Barghouthi, 2005] for an electric field of $50 \mathrm{mV}$ near $300 \mathrm{~km}$, corresponding to an ion drift speed of $\approx 1000 \mathrm{~m} / \mathrm{s}$. $\beta_{\|}=\beta_{\perp}=2 / 3$ corresponds to no anisotropy, and equations (4) and (5) then become identical to equation (3).

[42] The simplest anisotropy is a bi-Maxwellian distribution, in which the B-parallel and B-perpendicular crosssections of the thermal velocity distribution are still (unequal) Maxwellian distributions. We assume a bi-Maxwellian thermal distribution in the discussion of Figure 4c.

[43] Strong ion frictional heating may distort the thermal distribution into an entirely non-Maxwellian shape [St-Maurice and Schunk, 1977, 1979], which may lead to an underestimate of $T_{i}$ due to poor radar spectrum fitting since the default incoherent scatter radar analysis assumes a Maxwellian thermal distribution cross-section. This effect is more pronounced in the field-perpendicular direction than in the fieldparallel direction, and is not expected to be significant for the level of heating observed in the data presented here [Lockwood et al., 1993]. Strong ion frictional heating may also heat different ion species to different temperatures, as well as increase the percentage of molecular ions in the F region [McCrea et al., 1991; Lockwood et al., 1993]. To avoid this effect on a distortion of the temperatures derived from a bi-Maxwellian assumption, we have limited temperatures presented here to only above about $250 \mathrm{~km}$, and have limited temperatures used for the sensitive calculation of outflows to only values above $300 \mathrm{~km}$.
[44] We used the calculated $T_{n}$ in Figure 5 with the measured $T_{i \|}$ in equation (4) to calculate $\left|v_{i \perp}-v_{n}\right|$ for three possible values of $\beta_{\|}$, shown in Figure $4 \mathrm{c}$. Due to the quadratic relationship in equation (4), it is not possible to reliably calculate relative ion drifts of less than $\sim 500 \mathrm{~m} / \mathrm{s}$, corresponding to a 100-200 K ion temperature enhancement [Davies et al., 1995]. Those data points as well as those used to average $T_{n}$ have been excluded from the plot.

[45] The lower graph in Figure $4 \mathrm{c}$ corresponds to no anisotropy, i.e. $\beta_{\|}=2 / 3$. The middle graph shows $\left|v_{i \perp}-v_{n}\right|$ for $\beta_{\|}=0.3364$ [St-Maurice and Schunk, 1977]. The upper graph shows the $\beta_{\|}=0.22$ [Winkler et al., 1992]. We also calculated the 3D $T_{i}$ (not shown) for these three values of $\beta_{\|}$. $\beta_{\|}=0.3364$ produced $T_{i} \sim T_{e}$ for E2, E3 and E4, and $T_{i}>T_{e}$ for E1. For $\beta_{\|}=0.22$ we found $T_{i}>T_{e}$ for all events E1-E4.

[46] At all times, and at all altitudes at and above which $T_{i}$ only increases with height, heat flows from the electron gas to the ions, and any $\beta_{\|}$that would put $T_{i}$ greater than $T_{e}$ can be ruled out as giving a physically unrealistic answer. Only on those rare occasions, and then only at and below heights where $T_{i}$ decreases with increasing altitude, is the $\left|v_{i \perp}-v_{n}\right|$ so great (and thus $T_{i}$ is so heated) that heat flows from ions to the electrons (and $T_{i}$ is allowed to exceed $T_{e}$ ). We find that $\beta_{\|}=0.22$ is an unrealistic value for these measurements, and that $\beta_{\|}=0.3364$ may also be too large anisotropy for E1. It is possible that the proper value of $\beta_{\|}$ changes somewhat during the experiment, due to changing temperatures and densities.

[47] The spread in velocity for different values of $\beta_{\|}$is considerable. The red curve, corresponding to $\beta_{\|}=0.22$, gives the highest velocity, up to $2000 \mathrm{~m} / \mathrm{s}$ during the largest ion heating events.

[48] Prolonged ion frictional heating will transfer momentum from the ion gas to the neutral gas, changing the neutral dynamics. Baron and Wand [1983] calculated an $F$ region ion drag time constant of 38 minutes for $n_{e}=1 \times$ $10^{12} \mathrm{~m}^{-3}$. The same calculation gives $\tau \approx 190$ minutes for $n_{e}=1.8 \times 10^{11}\left(=10^{11.26}\right) \mathrm{m}^{-3}$, the maximum density observed in our data. We would therefore expect no significant influence on the neutral atmosphere from the ionosphere in the time period of our observations. A model study by Davies et al. [1995] further supports this assumption. We can therefore assume that the neutral temperature and wind are essentially constant for the hour we are studying. We do note, however, that Maeda et al. [2009] reported a rapid turning of the neutral wind, of about 20 minutes at an altitude range of $300-400 \mathrm{~km}$, in a flow channel when $n_{e} \approx 10^{11} \mathrm{~m}^{-3}$, comparable to densities we observe. The observed turning occurred in a persistent flow channel, while the flow events reported in this paper are significantly shorter in duration and we do not expect a similar influence on the neutral wind.

\subsection{Ambipolar Diffusion}

[49] $T_{e}$ intensifications lead to thermal upwelling of the electron gas, changing the electron gas scale height and resulting in an ambipolar electric field that drags the ions upward. From Schunk and Nagy [2009] we have (omitting the ion stress tensor gradient)

$$
v_{A \|}=v_{n \|}-\frac{2 k T_{p}}{m_{i} \nu_{i n}}\left(\frac{1}{n_{i}} \nabla_{\|} n_{i}+\frac{1}{T_{p}} \nabla_{\|} T_{p}-\frac{m_{i} g_{\|}}{2 k T_{p}}\right)
$$




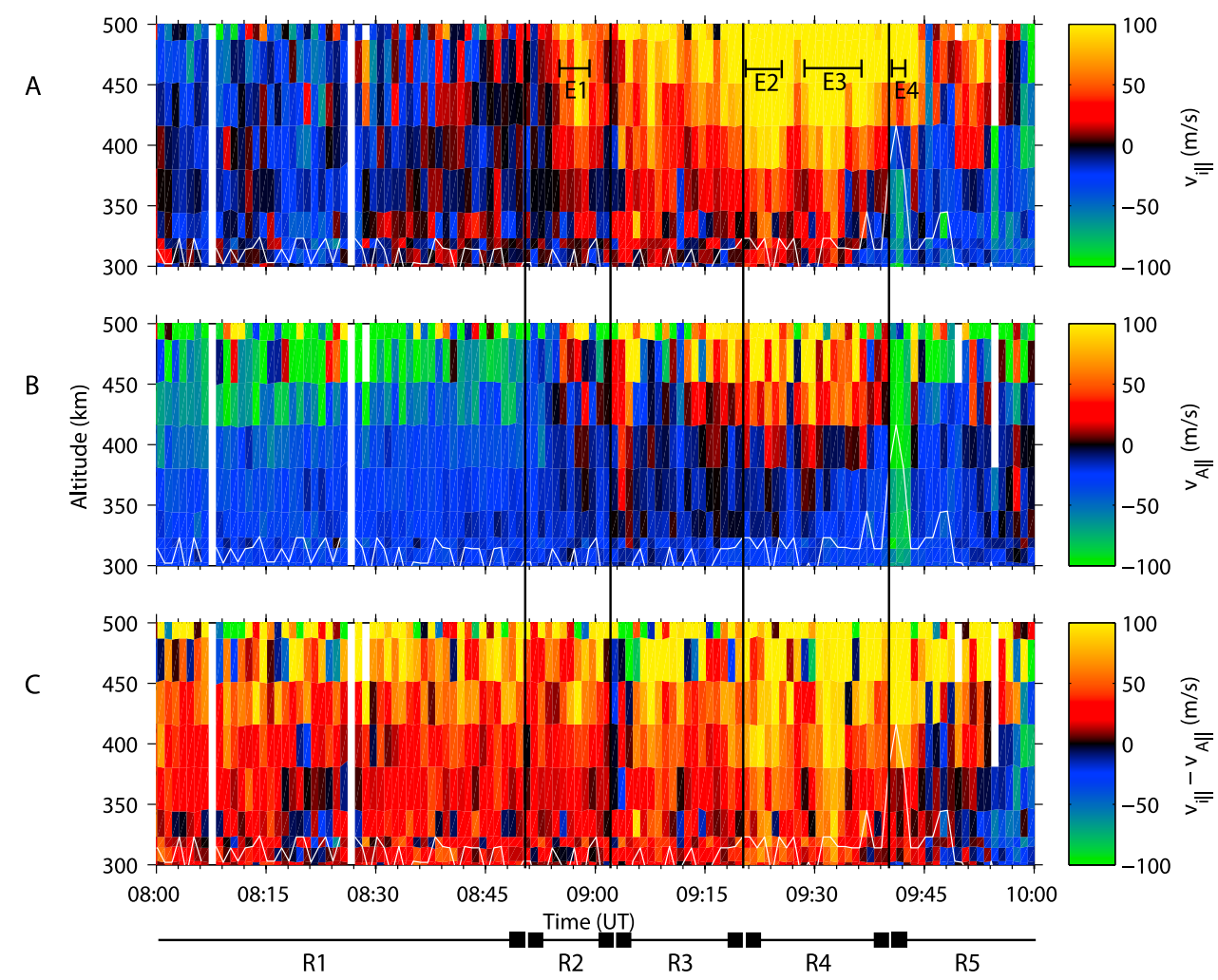

Figure 6. (a) Measured ion upflow, (b) calculated ambipolar upflow, and (c) difference. White lines show altitude of F2 electron density maximum. Regions and times of ion heating events marked as in Figure 2.

where $n_{i}$ is the ion number density, here assumed to be everywhere identical to the electron density $n_{e}$. The plasma temperature is defined as $T_{p}=\left(T_{i}+T_{e}\right) / 2, v_{A \|}$ is the fieldaligned ambipolar ion velocity, $v_{n \|}$ is the field-aligned component of the neutral wind, $g_{\|}$is the component of gravity parallel to the geomagnetic field, and $m_{i}$ is the mean mass of a single ion. We will assume a pure $\mathrm{O}^{+}$ionosphere in the following discussion.

[50] Results are shown in Figure 6, where we have assumed $v_{n \|}=0$. Figure 6a shows the measured ion upflow, and Figure $6 \mathrm{~b}$ shows the ion calculated upflows resulting from the ambipolar diffusion alone (equation (8)). Figure 6c shows the difference between the two results. Only data from above $300 \mathrm{~km}$ are shown to avoid any question about ion composition below this altitude. Above $500 \mathrm{~km}$ the statistical error bars become too large to extract meaningful data from the calculation.

[51] We used the parallel temperature component $T_{i \|}$ in calculating Figure 6, as it is the field-aligned component of the thermal velocity that contributes to field-aligned ambipolar upflow.

[52] We see that the calculated ambipolar upflow in Figure $6 \mathrm{~b}$ is less intense than the observed upflow (Figure 6a), and generally starts at $50-100 \mathrm{~km}$ above the upflow observed by the radar.

[53] The ambipolar diffusion calculation predicts downward movement of the plasma in region 1 . Such downward movement was observed, but weaker than predicted (Figure 6). We experimented with adding a constant bias to the calculated ambipolar diffusion in an attempt to make region 1 in Figures $6 \mathrm{a}$ and $6 \mathrm{~b}$ as similar as possible, and found a bias of $\sim+25 \mathrm{~m} / \mathrm{s}$ was the best overall match. This is a noticeable but not very large discrepancy. One possible explanation is that $v_{n \|}$ is not zero. A horizontal neutral wind with a southward component $\sim 160 \mathrm{~m} / \mathrm{s}$ would have a fieldaligned component $\sim 25 \mathrm{~m} / \mathrm{s}$.

[54] Another possibility is that there is a vertical neutral wind due to "neutral cooking", where upflowing ions drag the neutral gas along [Sadler et al., 2010], enhancing the neutral wind term in equation (8). Sadler et al. [2010] suggested that this was a slow process, requiring a "cooking time" of 10-30 minutes to achieve a steady-state neutral density enhancement. If it is possible that such "cooking" is happening in the aurora, that might explain some of the discrepancy between $v_{i \|}$ and $v_{A}$ in Figure 6c.

[55] The upflow related to E1 at 08:55-08:58 is visible in Figure $6 \mathrm{c}$ at $420 \mathrm{~km}$ altitude as a brief strong deviation from the ambipolar upflow. We see that the observed upflow exceeds the ambipolar by more than $100 \mathrm{~m} / \mathrm{s}$ in the large upflow related to E2-E3.

[56] We can now estimate the ambipolar contribution to the ion upflows associated with the ion heating events E1-E3. (E4 is at too high altitude.) For E1 the ambipolar contribution is $\sim 30 \%$ and for E2 and E3 it is $\sim 50-60 \%$ of the total upflow. Subtracting the neutral wind bias found earlier does not change this significantly.

\subsection{Ion Heating Around/in Optical Arcs}

[57] The ion upflows related to E1-E4 in Figures 2 and 4 all appear to have a V-shape in time-altitude (Figure 2d), and 
Moen et al. [2004a] suggested that the upflows were connected to inverted $\mathrm{V}$ potential structures convecting across the radar beam. The presence of ion heating near PMAFs in our data suggests the presence of current systems causing local flow modulation. High-resolution observations of the cusp flow have found that the ion flow contains structures and that flow reversals are a common feature (cf. introduction). Since we have no direct high resolution flow measurements, but only the scalar of $\left|v_{i \perp}-v_{n}\right|$ indirectly derived from $T_{i \|}$ which is not suitable to further characterize the flow bursts, we will refer to these as "flow events" in the remainder of the text.

[58] In the case studied here, IMF $B_{y}$ was positive and the polar cap intake region was shifted toward dawn, as seen in Figure 3. Assuming that flow events move in the same direction as the general polar cap convection, flow events passing over Svalbard would then convect northwestward toward the intake region.

[59] E1 occurred in region 2, when the radar beam was equatorward of the steady cusp aurora. $T_{i \|}$ was observed to rise from $950 \mathrm{~K}$ at 08:52 to nearly $2000 \mathrm{~K}$ at 08:57 before gradually subsiding to $1100 \mathrm{~K}$ at $09: 01$. The increase in $T_{i \|}$ can be seen in Figure 4 to correspond to a peak ion-neutral relative velocity of roughly $1000-1200 \mathrm{~m} / \mathrm{s}$ for a $\beta_{\|}=2 / 3$ (no anisotropy). The event was accompanied by ion upflow of about $100 \mathrm{~m} / \mathrm{s}$. We identify the upflow in E1 as driven by thermal upwelling of ions. Confusion of the MSP optical signature was introduced by a brief optical feature directly over the radar at 08:58, identified by the ASC image as an isolated auroral filament convecting westward. The precipitating electrons exciting this isolated transient are seen as a single enhanced $T_{e}$ in one data point in the minute after the peak ion-neutral relative velocity (due to no coincident $T_{i \|}$ enhancement). The signature of this filament is an isolated feature in the ASC, and should cause enhanced $T_{e}$ only. The flow channel signatures include extended poleward moving optical signatures, and coincident enhancements of $T_{i \|}$ as expected from frictional drag heating.

[60] The ion upflow in region 3 is somewhat structured in time but there is not a clear correspondence between distinct peaks in $T_{i \|}$ or $T_{e}$ and upflow as there was for E1. There are three instances of $T_{i \|}$ in region 3 exceeding $1400 \mathrm{~K}$ at $302 \mathrm{~km}$, in each case lasting only one integration period. They occur at 09:02, 09:12 and 09:17 UT. We considered these too small to be separate events. We note that while they look almost identical in the temperature plot (Figure 4a) their relation to optical events are quite different: The 09:02 temperature peak occurred an integration period before a PMAF entered the beam, the 09:12 peak occurred while there was no strong optical event and the 09:17 peak occurred immediately equatorward of a PMAF. We should point out that for the 09:17 PMAF the choice of auroral emission altitude affects the location of the PMAF relative to the radar (cf. Figure 4d). However, this is not a significant point in the overall discussion.

[61] The upflow that exists in this region is comparable to that of E1. $T_{i \|}$ was only enhanced to about $1200-1300 \mathrm{~K}$, while $T_{e}$ varied between 2000 and $3000 \mathrm{~K}$. This suggests that ambipolar diffusion should be the primary driver of ion upflow in this region. Figure $6 \mathrm{c}$ suggests that another mechanism was active and could contribute a measurable fraction of the upflow also here. We suggested neutral wind effects in section 4.2 .

[62] In region 4 both $T_{e}$ and $T_{i \|}$ were enhanced, and the magnitude of upflow increased greatly, from between 100 $200 \mathrm{~m} / \mathrm{s}$ to between $200-500 \mathrm{~m} / \mathrm{s}$. Two episodes of increased $T_{i \|}$ were identified: E2 from 09:20 to 09:25 UT, E3 from 09:28 to 09:36 UT. These may be parts of a single large $T_{i \|}$ intensification interrupted by small-scale flow reversals. Each of these $T_{i \|}$ heating events was associated with strong ion upflow, and at higher altitudes there were also noticeable enhancements of $T_{e}$. The combined contributions of elevated $T_{e}$ and $T_{i \|}$ appear to give significantly stronger upflow than $T_{e}$ alone or $T_{i \|}$ alone. This seems reasonable since in these cases ambipolar diffusion and ion upwelling work together to lift the ion gas. We note that the peak $T_{i \|}$ and $v_{i \|}$ values in E3 did not occur within the intense optical events, but rather on the edges as the beam entered or exited the optical feature.

[63] E4 between 09:40-09:42 is different from E2 and E3 in some respects. PMAF activity had ceased, and auroral structures were now convecting westward. The radar beam was located near the poleward edge of the cusp aurora. Simultaneous with E4 we observed a greatly elevated F2 layer peak altitude of $\sim 400 \mathrm{~km}$, compared to $\sim 300 \mathrm{~km}$ for other times, and an upflow/downflow reversal around the F2 peak, similar to events described by Davies et al. [1995]. The enhanced downflow below the F2 peak in this event appears to be due to the enhanced ambipolar diffusion, similar to what Davies et al. [1995] found. The downflow is less intense than predicted from ambipolar diffusion alone (see Figure 6), suggesting that thermal upwelling may be counteracting the ambipolar downflow. We also note that according to temperatures this is a type 2 upflow. In contrast, the $\mathrm{F}$ layer lifting in the nightside aurora observed by Wahlund et al. [1992] was interpreted as a feature typical of type 1 upflows.

[64] The upflows observed prior to E4 were associated with a sequence of PMAFs. The PMAFs took around 3 to 5 minutes to cross the cusp aurora, and were seen by the radar relatively early in their evolution. The prominent poleward moving auroral forms stopped around 09:35 after which the auroral events had a predominantly westward motion consistent with the SuperDARN convection maps. It is not possible to tell from optical data how long E4 had evolved prior to entering the radar beam, but the lifted $F$ layer peak gives a clue. An elevation of the density structure by $100 \mathrm{~km}$ corresponds to 4 minutes of vertical motion at a constant field-aligned velocity of $400 \mathrm{~m} / \mathrm{s}$. Hence, E4 may then be an event similar to the E2 and E3, but which entered the radar beam at a later time in its evolution. It may have been tied to a westward-moving auroral form. East-west moving transients in the cusp such as PMAFs are regarded as a footprint of pulsed magnetopause reconnection (FTEs) [Moen et al., 1996b, 1998, 1999].

\subsection{Type 1 and Type 2 Outflows}

[65] We wish to note that while the two physically separable drivers of plasma outflow, ion gas frictional heating and electron gas particle heating, follow from importantly different physical heating mechanisms, a further consideration is called for. In Figure $4 \mathrm{~b}$, we can note the observational fact that during R1 our measured $v_{i \|}$ varied about zero 
(within $\pm 70 \mathrm{~m} / \mathrm{s}$ ), in $\mathrm{R} 2$ it varied (within statistical error bars) between about 0 and over $100 \mathrm{~m} / \mathrm{s}$; in R3 it varied between 0 and $150-200 \mathrm{~m} / \mathrm{s}$; and in R4 between 100 -over $300 \mathrm{~m} / \mathrm{s}$. In R4, where $v_{i \|}$ reached its highest values, both $T_{e}$ and $T_{i \|}$ were elevated relative to their values in R1. In R5 $T_{i \|}$ fell and approached its value in $\mathrm{R} 1$, while $T_{e}$ near the poleward edge was somewhat elevated. Separating boundaries of particle precipitation vs. velocity channels is highly challenging, viz. Lanchester et al. [1996] addressing the issue in the nightside aurora, and is also challenging in the cusp we address even though the cusp is less temporally and spatially structured. $T_{e}$ has a time constant of about 30 seconds (time to reach within 1/e of steady state value at a constant heating rate) in the $F$ region both as per theory and as measured [Mantas et al., 1981], and $T_{i}$ likewise as discussed herein. Thus neither is a direct measure of instantaneous heating mechanism per se, but each temperature of finite temporal response does enter into the plasma transport equations. We would note that where $T_{e}$ and $T_{i \|}$ were both observed within the radar beam to be elevated, the radar beam observed the highest outflow velocities. While separating the two types of outflow is essential to the concept of separating heating mechanisms, these observations illustrate volumes (as just defined) of plasma whose greatest outflow velocity is measured when measured values of both $T_{e}$ and $T_{i}$ are elevated.

\section{Summary and Concluding Remarks}

[66] We have presented ion heating events measured as they were created near the equatorward edge of the cusp aurora, within the cusp aurora, and on the poleward edge of the cusp aurora. All ion heating events were associated with ion upflow. In general the strongest upflow was seen within the cusp aurora, in association with poleward moving auroral forms, when both $T_{e}$ and $T_{i \|}$ were enhanced. Large $T_{i \|}$ enhancements could be identified as distinct events. $T_{e}$ was more continuously enhanced and could not easily be separated into distinct events, particularly in the middle of the cusp aurora. A quiet period in the beginning of our data set allowed us to estimate $T_{n}$ from $T_{i \|}$. We found that $T_{n}$ was close to the value predicted by the MSIS86 value, and we were then able to use the measured value to estimate the magnitude of the $\mathbf{B}$-perpendicular ion flow relative to the neutral wind. We were also able to offer some insight into $T_{i}$ anisotropy during ion frictional heating. We find that $\beta_{\|} \geq$ 0.3364 (value suggested by St-Maurice and Schunk [1977]) in the case we examine.

[67] Our study highlights the importance of supporting optical data when studying the aurora by radar. Without the MSP data, we would not have been able to reliably identify when we were observing the different parts of the aurora, and how upflows were related to auroral structures.

[68] Events were classified according to the type 1 and type 2 definition introduced by Wahlund et al. [1992]. Type 1 upflow events are associated with elevated $T_{i \|}$ and being driven by frictional heating of the ion gas. Type 2 is driven by particle precipitation, electron heating and ambipolar diffusion.

[69] We observed a type 1 event on the equatorward side of the cusp aurora, in a region lacking soft particle precipitation (cf. E1 in Figures 2 and 4). Next we observed type 2 upflow near the equatorward edge of the cusp aurora, in a region which the electron temperature was greatly elevated by soft particle precipitation, but were lacking significant ion heating (cf. region 3 in Figures 2 and 4). In this region the ion upflow was of the same order as calculated for ambipolar diffusion.

[70] Inside the cusp aurora the strongest upflows were seen associated with simultaneously elevated $T_{e}$ and $T_{i \|}$ (cf. region 4 in Figures 2 and 4). The ambipolar diffusion in this region could only contribute $50-60 \%$ of the observed ion upflow speeds. We conclude that these upflows were due to the combined effect of frictional heating and ambipolar diffusion, i.e. the type 1 and type 2 event categories may coexist.

[71] The event labeled E3 (Figures 2 and 4) occurred when the radar beam passed through a large PMAF which was itself embedded in the cusp aurora. Zooming in on E3 and the associated PMAF we found that the peak ion upflow and ion temperature did not appear to coincide with peak optical activity but rather occurred near the edges of the optical event. This is consistent with $T_{i \|}$ being an important contributor to upflow, since the ion frictional enhancement of $T_{i \|}$ will be smaller at the flow shear underneath a Birkeland current sheet than immediately outside the current.

[72] The very rapidly changing $T_{i \|}$ observed in the center of the aurora suggests the presence of structured flow on the order of or smaller than the radar's resolution (changes in $T_{i \|}$ are expected to correspond to changes in flow via ion frictional heating). One candidate contributor is the class of event called reversed flow events (RFEs) [e.g., Oksavik et al., 2004; Rinne et al., 2007; Moen et al., 2008] These are narrow channels of rapid reversed flow, i.e. opposing the large-scale ion flow, that have been observed in the cusp ionosphere. Although the events themselves have a lifetime of 10-20 minutes and are aligned roughly along L-shells, they can move poleward, and small such events could plausibly cause the sudden "switching off" of $T_{i \|}$ enhancement seen by the field-aligned radar when they cross the beam.

[73] The type 1 and type 2 upflow classifications introduced by Wahlund et al. [1992] were based on observations of the auroral zone using the mainland EISCAT radars. As such, the events they studied were nightside upflows. The events examined in this paper occurred under the dayside cusp, where energy input is generally smaller and particle precipitation softer. The softer precipitation will deposit its energy at higher altitudes, where a small energy input can have dramatically larger effect than at lower altitudes [Carlson, 1998, 2007]. The thermal response times here in the cusp are on the order of a minute [Carlson, 1998, 2007; Carlson et al., 2004], the same as the integration time of the radar.

[74] Acknowledgments. EISCAT is an international association supported by research organizations in China (CRIRP), Finland (SA), France (CNRS, until end 2006), Germany (DFG), Japan (NIPR and STEL), Norway (NFR), Sweden (VR), and the United Kingdom (STFC). We wish to thank Ivan Finch and Ian McCrea (Rutherford-Appleton Laboratory) for their most kind and helpful assistance in acquiring and analyzing EISCAT data. We also wish to thank D. Boscher and S. Bourdarie (ONERA-DESP, Toulouse, France), and P. O'Brien and T. Guild (Aerospace Corporation, Washington DC, USA) for providing the ONERA-DESP library, which contains the MSIS86 implementation used in preparing this publication. 
We thank Keisuke Hosokawa for providing Figure 3. Last, we wish to thank Espen Trondsen and Bjørn Lybekk (University of Oslo) for providing the optical data from $\mathrm{Ny}$-Ålesund. The project has been supported by the Norwegian Research Council, the Air Force Office of Scientific Research, Air Force Material Command, USAF, under grant FA8655-10-1-3003, and COST action ES0803, and by the Utah State USTAR program.

[75] Robert Lysak thanks the reviewers for their assistance in evaluating this paper.

\section{References}

Barghouthi, I. A. (2005), $\mathrm{O}^{+}$ion temperature partition coefficients $\beta_{\|}$and $\beta_{\perp}$ : The effect of $\mathrm{O}^{+}-\mathrm{O}^{+}$coulomb self-collisions, J. Geophys. Res. 110, A06307, doi:10.1029/2004JA010475.

Baron, M. J., and R. H. Wand (1983), F region ion temperature enhancements resulting from joule heating, J. Geophys. Res., 88(A5), 4114-4118.

Carlson, H. C. (1996), Incoherent scatter radar mapping of polar electrodynamics, J. Atmos. Terr. Phys., 58(1), 37-56.

Carlson, H. C. (1998), Response of the polar cap ionosphere to changes in (solar wind) IMF, in Polar Cap Boundary Phenomena, edited by J. Moen, A. Egeland, and M. Lockwood, pp. 255-270, Kluwer Acad., Dordrecht, Netherlands.

Carlson, H. C. (2007), Role of neutral atmospheric dynamics in cusp density and ionospheric patch formation, Geophys. Res. Lett., 34, L13101, doi:10.1029/2007GL029316.

Carlson, H. C., K. Oksavik, J. Moen, and T. Pedersen (2004), Ionospheric patch formation: Direct measurements of the origin of a polar cap patch, Geophys. Res. Lett., 31, L08806, doi:10.1029/2003GL018166.

Cowley, S. W. H., and M. Lockwood (1992), Excitation and decay of solar wind-driven flows in the magnetosphere-ionosphere system, Ann. Geophys., 10, 103-115.

Davies, J. A., M. Lester, B. Jenkins, and R. J. Moffett (1995), Dayside ion frictional heating: EISCAT observations and comparison with model results, J. Atmos. Terr. Phys., 57(7), 775-793.

Doe, R. A., J. D. Kelly, and E. R. Sánchez (2001), Observations of persistent dayside $\mathrm{F}$ region electron temperature enhancements associated with soft magnetosheathlike precipitation, J. Geophys. Res., 106, 3615-3630.

Endo, M., R. Fujii, Y. Ogawa, S. C. Buchert, S. Nozawa, S. Watanabe, and N. Yoshida (2000), Ion upflow and downflow at the topside ionosphere observed with EISCAT VHF radar, Ann. Geophys., 18, 170-181.

Fasel, G. (1995), Dayside poleward-moving auroral forms: A statistical study, J. Geophys. Res., 100, 11,891-11,905.

Fedder, J. A., and P. M. Banks (1972), Convection electric fields and polar thermospheric winds, J. Geophys. Res., 77(13), 2328-2340.

Hedin, A. E. (1987), MSIS-86 thermospheric model, J. Geophys. Res., 92(A5), 4649-4662.

Lanchester, B. S., K. Kaila, and I. W. McCrea (1996), Relationship between large horizontal electric fields and auroral arc elements, J. Geophys. Res. 101(A3), 5075-5084, doi:10.1029/95JA02055.

Lockwood, M., and M. N. Wild (1993), On the quasi-periodic nature of magnetopause flux transfer events, J. Geophys. Res., 98(A4), $5935-5940$.

Lockwood, M., I. W. McCrea, G. H. Millward, R. J. Moffett, and H. Rishbeth (1993), EISCAT observations of ion composition and temperature anisotropy in the high-latitude F region, J. Atmos. Terr. Phys., $55(6), 895-906$

Lockwood, M., I. W. McCrea, S. E. Milan, J. Moen, J. C. Cerisier, and A. Thorolfsson (2000), Plasma structure within poleward-moving cusp/cleft auroral transients: EISCAT Svalbard radar observations and an explanation in terms of large local time extents of events, Ann. Geophys., 18, 1027-1042.

Lorentzen, D. A., and J. Moen (2000), Auroral proton and electron signatures in the dayside aurora, J. Geophys. Res., 105, 12,733-12,745.

Maeda, S., Y. Ogawa, K. Hosokawa, S. Nozawa, S. Oyama, T. Tsuda, and A. Brekke (2009), Ion heating in high-speed flow channel within the duskside cell of the polar cap ion convection under large IMF- $B_{y}$ condition, J. Geophys. Res., 114, A11307, doi:10.1029/2009JA014300.

Mantas, G., H. Carlson, and C. LaHoz (1981), Thermal response of the $F$ region ionosphere in artificial modification experiments by HF radio waves, J. Geophys. Res., 86, 561-574.

McCrea, I. W., M. Lester, T. R. Robinson, N. M. Wade, and T. B. Jones (1991), On the identification and occurrence of ion frictional heating events in the high-latitude ionosphere, J. Atmos. Terr. Phys., 53(6-7), 587-597.

McCrea, I. W., M. Lester, T. R. Robinson, J.-P. St-Maurice, N. M. Wade, and T. B. Jones (1993), Derivation of the ion temperature partition coefficient $\beta_{\|}$from the study of ion frictional heating events, $J$. Geophys. Res., 98(A9), 15,701-15,715.
McCrea, I. W., G. O. L. Jones, and M. Lester (1995), The BEAN experiment-An EISCAT study of ion temperature anisotropies, Ann. Geophys., 13(2), 177-188.

McCrea, I. W., M. Lockwood, J. Moen, F. Pitout, P. Eglitis, A. D. Aylward, J.-C. Cerisier, A. Thorolfssen, and S. E. Milan (2000), ESR and EISCAT observations of the response of the cusp and cleft to IMF orientation changes, Ann. Geophys., 18, 1009-1026.

Moen, J., P. E. Sandholt, M. Lockwood, W. F. Denig, U. P. Løvhaug, B. Lybekk, A. Egeland, D. Opsvik, and E. Friis-Christensen (1995), Events of enhanced convection and related dayside auroral activity, J. Geophys. Res., 100(A12), 23,917-23,934.

Moen, J., M. Lockwood, P. E. Sandholt, U. P. Løvhaug, W. F. Denig, A. Egeland, and A. P. van Eyken (1996a), Variability of dayside high latitude convection associated with a sequence of auroral transients, J. Atmos. Terr. Phys., 58,85-95.

Moen, J., D. Evans, H. C. Carlson, and M. Lockwood (1996b), Dayside moving auroral transients related to LLBL dynamics, Geophys. Res. Lett., 23, 3247-3250.

Moen, J., D. A. Lorentzen, and F. Sigernes (1998), Dayside moving auroral forms and bursty proton auroral events in relation to particle boundaries observed by NOAA 12, J. Geophys. Res., 103, 14,855-14,863.

Moen, J., H. C. Carlson, and P. E. Sandholt (1999), Continuous observation of cusp auroral dynamics in response to an IMF $B_{y}$ polarity change, Geophys. Res. Lett., 26(9), 1243-1246.

Moen, J., A. P. van Eyken, and H. C. Carlson (2001), EISCAT Svalbard radar observations of ionospheric plasma dynamics in relation to dayside auroral transients, J. Geophys. Res., 106(A10), 21,453-21,461.

Moen, J., K. Oksavik, and H. C. Carlson (2004a), On the relationship between ion upflow events and cusp auroral transients, Geophys. Res. Lett., 31, L11808, doi:10.1029/2004GL020129.

Moen, J., M. Lockwood, K. Oksavik, H. C. Carlson, W. F. Denig, A. P. van Eyken, and I. W. McCrea (2004b), The dynamics and relationships of precipitation, temperature and convection boundaries in the dayside auroral ionosphere, Ann. Geophys., 22, 1973-1987.

Moen, J., H. C. Carlson, K. Oksavik, C. P. Nielsen, S. E. Pryse, H. R. Middleton, I. W. McCrea, and P. Gallop (2006), EISCAT observations of plasma patches at sub-auroral cusp latitudes, Ann. Geophys., 24, 2363-2374.

Moen, J., N. Gulbrandsen, D. A. Lorentzen, and H. C. Carlson (2007), On the MLT distribution of F-region polar cap patches at night, Geophys. Res. Lett., 34, L14113, doi:10.1029/2007GL029632.

Moen, J., Y. Rinne, H. Carlson, K. Oksavik, R. Fujii, and H. Opgenoorth (2008), On the relationship between thin Birkeland current arcs and reversed flow channels in the winter cusp/cleft ionosphere, J. Geophys. Res., 113, A09220, doi:10.1029/2008JA013061.

Ogawa, Y., R. Fujii, S. C. Buchert, S. Nozawa, and S. Ohtani (2003), Simultaneous EISCAT Svalbard radar and DMSP observations of ion upflow in the dayside polar ionosphere, J. Geophys. Res., 108(A3), 1101, doi:10.1029/2002JA009590.

Ogawa, Y., S. C. Buchert, R. Fujii, S. Nozawa, and A. P. van Eyken (2009), Characteristics of ion upflow and downflow observed with the European Incoherent Scatter Svalbard radar, J. Geophys. Res., 114, A05305, doi:10.1029/2008JA013817.

Oksavik, K., J. Moen, and H. C. Carlson (2004), High-resolution observations of the small-scale flow pattern associated with a poleward moving auroral form in the cusp, Geophys. Res. Lett., 31, L11807, doi:10.1029/ 2004GL019838.

Oksavik, K., J. Moen, H. C. Carlson, R. A. Greenwald, S. E. Milan, M. Lester, W. F. Denig, and R. J. Barnes (2005), Multi-instrument mapping of the small-scale flow dynamics related to a cusp auroral instrument, Ann. Geophys., 23, 2657-2670.

Pinnock, M., A. S. Rodger, J. R. Dudeney, K. B. Baker, P. T. Newell, R. A. Greenwald, and M. E. Greenspan (1993), Observations of an enhanced convection channel in the cusp ionosphere, J. Geophys. Res., 98(A3), 3767-3776.

Pinnock, M., A. S. Rodger, J. R. Dudeney, F. Rich, and K. B. Baker (1995), High spatial and temporal resolution of the ionospheric cusp, Ann. Geophys., 13, 919-925.

Provan, G., T. K. Yeoman, and S. E. Milan (1998), CUTLASS Finland radar observations of the ionospheric signatures of flux transfer events and the resulting plasma flows, Ann. Geophys., 16, 1411-1422.

Provan, G., T. K. Yeoman, S. E. Milan, J. M. Ruohoniemi, and R. Barnes (2002), An assessment of the "map-potential" and "beam-swinging" techniques for measuring the ionospheric convection pattern using data from the SuperDARN radars, Ann. Geophys., 20(2), 191-202.

Pryse, S. E., R. W. Sims, J. Moen, L. Kersley, D. Lorentzen, and W. F. Denig (2004), Evidence for solar-production as a source of polar-cap plasma, Ann. Geophys., 22, 1093-1102. 
Rinne, Y., J. Moen, K. Oksavik, and H. C. Carlson (2007), Reversed flow events in the winter cusp ionosphere observed by the European Incoherent Scatter (EISCAT) Svalbard radar, J. Geophys. Res., 112, A10313, doi:10.1029/2007JA012366.

Ruohoniemi, J. M., and K. B. Baker (1998), Large-scale imaging of highlatitude convection with Super Dual Auroral Radar Network HF radar observations, J. Geophys. Res., 103(A9), 20,797-20,811.

Ruohoniemi, J. M., and R. A. Greenwald (2005), Dependencies of highlatitude plasma convection: Consideration of interplanetary magnetic field, seasonal, and universal time factors in statistical patterns, J. Geophys. Res., A09204, doi:10.1029/2004JA010815.

Sadler, B., A. Otto, M. Lessard, E. J. Lund, and H. Luhr (2010), Auroral precipitation as a driver of neutral upwelling in the cusp, Abstract SM21C-06 presented at 2010 Fall Meeting, AGU, San Francisco, Calif., 13-17 Dec.

Sandholt, P. E., C. S. Deehr, A. Egeland, B. Lybekk, R. Viereck, and G. J. Romick (1986), Signatures in the dayside aurora of plasma transfer from the magnetosheath, J. Geophys. Res., 91, 10,063-10,079.

Sandholt, P. E., B. Lybekk, A. Egeland, R. Nakamura, and T. Oguti (1989), Midday auroral breakup, J. Geomagn. Geoelectr., 41, 371-387.

Sandholt, P. E., M. Lockwood, T. Oguti, S. W. H. Cowlet, K. S. C. Freeman, B. Lybekk, A. Egeland, and D. M. Willis (1990), Midday auroral breakup events and related energy and momentum transfer from the magnetosheath, J. Geophys. Res., 95(A2), 1039-1060.

Sandholt, P. E., J. Moen, A. Rudland, D. Opsvik, W. Denig, and T. Hansen (1993), Auroral event sequences at the dayside polar cap boundary for positive and negative IMF $B_{y}, J$. Geophys. Res., 98, 7737-7755.

Sandholt, P. E., C. J. Farrugia, J. Moen, Ø. Noraberg, B. Lybekk, T. Sten, and T. L. Hansen (1998), A classification of dayside auroral forms and activities as a function of IMF orientation, J. Geophys. Res., 103, $23,325-23,345$

Schunk, R., and A. Nagy (2009), Ionospheres: Physics, Plasma Physics, and Chemistry, 2nd ed., Cambridge Univ. Press, Cambridge, U. K.
Shelley, E. G., R. D. Sharp, and R. G. Johnson (1976), Satellite observations of an ionospheric acceleration mechanism, Geophys. Res. Lett., 3(11), 654-656.

Sigernes, F., J. Moen, D. Lorentzen, C. S. Deehr, R. Smith, M. Øieroset, B. Lybekk, and J. Holtet (1996), SCIFER-Height measurements of the midmorning aurora, Geophys. Res. Lett., 23(14), 1889-1892.

St-Maurice, J.-P., and R. W. Schunk (1977), Auroral ion velocity distributions for a polarization collision model, Planet. Space Sci., 25, 243-260.

St-Maurice, J.-P., and R. W. Schunk (1979), Ion velocity distributions in the high-latitude ionosphere, Rev. Geophys., 17(1), 99-134.

Strangeway, R. J., R. E. Ergun, Y.-J. Su, C. W. Carlson, and R. C. Elphic (2005), Factors controlling ionospheric outflows as observed at intermediate altitudes, J. Geophys. Res., 110, A03221, doi:10.1029/2004JA010829.

Vorobjev, V. G., G. Gustafsson, G. V. Starkov, Y. I. Feldstein, and N. F. Shernina (1975), Dynamics of the day and night aurora during substorms, Planet. Space Sci., 23, 269-278.

Wahlund, J.-E., H. J. Opgenoorth, I. Häggström, K. J. Winser, and G. O. L. Jones (1992), EISCAT observations of topside ionospheric ion outflows during auroral activity: Revisited, J. Geophys. Res., 97(A3), 3019-3037.

Wannberg, G., et al. (1997), The EISCAT Svalbard radar: A case study in modern incoherent scatter radar system design, Radio Sci., 32(6), 2283-2307.

Winkler, E., J.-P. St-Maurice, and A. R. Barakat (1992), Results from improved Monte Carlo calculations of auroral ion velocity distributions, J. Geophys. Res., 97(A6), 8399-8423.

H. C. Carlson, Space Weather Center, CASS, Utah State University, Logan, UT 84322, USA.

J. Moen and $\AA$. Skjæveland, Department of Physics, University of Oslo, Postboks 1048 Blindern, N-0316 Oslo, Norway. (asmund.skjaveland@fys. uio.no) 